\title{
Electrochemical Performances of Recycled AZ31 Magnesium Alloy in $\mathrm{NaCl}$ Solution
}

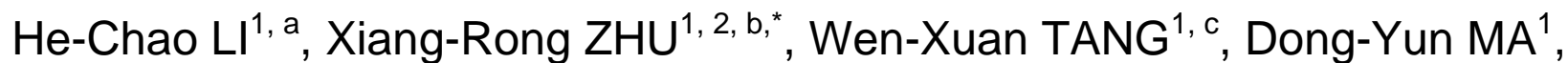 \\ Jin-Ming WANG ${ }^{1}$, Ya ZHANG ${ }^{3}$ and Qiu-Rong $\mathrm{CHEN}^{3}$
}

${ }^{1}$ School of environmental and materials engineering, College of Engineering, Shanghai Polytechnic University, Shanghai 201209, P.R.China

${ }^{2}$ Research Center of Resource Recycling Science and Engineering, Shanghai Polytechnic University, Shanghai 201209, P.R.China

${ }^{3}$ Shanghai Institute of Micro-system and Information Technology, Chinese Academy of Sciences, Shanghai 200050, P.R.China

a13122259548@163.com , bzhuxiangrong71@126.com, cjenny199886@163.com

${ }^{*}$ Corresponding author

Keywords: Recycled magnesium alloy, structure, electrochemical performance

\begin{abstract}
Recycled as-cast magnesium alloys were prepared by smelting method according to the nominal composition of AZ31 magnesium alloys. The structure and electrochemical properties of the recycled alloys were characterized and compared to those of the commercial as-cast AZ31 magnesium alloys. X-ray diffractometry patterns show that the main phases of the recycled alloy are $\alpha-\mathrm{Mg}$ solid solutions and the recycled alloys present more $\mathrm{Mg}_{17} \mathrm{Al}_{12}$ second phases than the commercialized alloy. Polarization curves results obtained from electrochemical experiments in 5\% $\mathrm{NaCl}$ solution indicate that the recycled alloy exhibits a bit higher corrosion current density than the commercialized alloy and similar negative equilibrium potential to the commercialized alloy. The recycled alloy performs the higher corrosion rate in $5 \% \mathrm{NaCl}$ solution and the worse corrosion resistance than the commercialized alloy according to self-corrosion rate and electrochemical impedance spectroscopy measurement results.
\end{abstract}

\section{Introduction}

At present, magnesium and its alloys are widely used in industrial field due to their unique physical, chemical and mechanical properties [1]. For example, the productions of magnesium are greatly used for manufacturing automobiles as one kind of light structural materials [2]. Besides the application for the structural materials, magnesium and its alloys might be also used for cell materials of chemical power sources because they possess high theoretical specific capacity, low standard electrode potential[2,3].

In recent years, with the extensive use of magnesium alloys, a large number of abandoned magnesium alloy materials have been produced, which would result in the environmental question. Thus it is vital to consider the recycling of the abandoned magnesium alloy materials. In fact, using the magnesium productions based on the recycled magnesium alloy materials would lower the materials cost and energy consumption $[4,5]$.

Numerous researches about the magnesium alloys are focused on the electrochemical performance when they are used as the negative electrode materials of magnesium batteries. Deng studied the electrochemical performances of commercialized AZ31 alloys and found the extruded alloys presented good electrochemical activity, which possessed more negative equilibrium potential, low corrosion current density and small free corrosion rate [6]. The electrochemical performances of other magnesium alloys such as AM50 and ZAX310 were also researched [7]. Although the magnesium negative electrode materials are always commercialized alloys, the recycled magnesium alloys could be considered to use for the negative electrode materials if they have proper electrochemical performance similar to the commercialized alloys. 
In this paper, the electrochemical properties of the recycled as-cast AZ31 magnesium alloys were studied and compared to those of the commercialized as-cast AZ31 alloy. The researches explored the application potential of the recycled magnesium alloys as negative electrode materials in magnesium battery.

\section{Materials and Methods}

The nominal composition of the magnesium alloys used in this paper is based on the national standards of AZ31 magnesium alloy, which are Al 3.31 wt.\%, Zn 0.82 wt.\%, Mn 0.27 wt.\%, Fe 0.002 wt.\%, $\mathrm{Cu} 0.004$ wt.\%, Ni 0.0007 wt.\% and rest $\mathrm{Mg}$ for the recycled as-cast magnesium alloys, and $\mathrm{Al} 2.70$ wt.\%, Zn 0.80 wt.\%, Mn 0.30 wt.\%, Fe 0.001 wt.\%, Cu 0.0006 wt.\%, Ni 0.0003 wt.\% and rest $\mathrm{Mg}$ for the commercialized as-cast AZ31 magnesium alloy. Ingots of the recycled magnesium alloy were prepared by smelting method via a medium-frequency induction-heating furnace. During the smelting technique, the protecting gas was Ar. The size of the as-cast ingot of recycled magnesium alloy was $\Phi 120 \mathrm{~mm} \times 400 \mathrm{~mm}$.

Surface microstructure of the samples was observed by optical microscopy (OM). The crystal structure of the samples was measured by X-ray diffractometry (XRD), which can perform the phase classification of the alloys. The XRD patterns were obtained using Rigaku D/max2200vpc $\mathrm{X}$-Ray diffractometer in the range of $10^{\circ}-100^{\circ}$ at a scan rate of $2^{\circ} / \mathrm{min}$.

Electrolyte used in the electrochemical experiment was $5 \%$ (wt. \%) $\mathrm{NaCl}$ solution. Firstly, the self -corrosion characteristics of the samples were measured. The self-corrosion rate can evaluate the corrosion resistance of materials. During the self-corrosion experiment, the samples were immerged in 5\% NaCl electrolyte for $168 \mathrm{hrs}$. After that, the corrosion samples were cleaned by chromic acid of $250 \mathrm{~g} / \mathrm{L}$ and then were weighed. The self-corrosion rate can be expressed as following equation:

$$
V=\frac{m_{0}-m_{1}}{S \times t}
$$

Where $v$ is the corrosion rate $\left(\mathrm{mg} \cdot \mathrm{h}^{-1} \cdot \mathrm{cm}^{-2}\right), m_{0}$ is the initial mass of the sample $(\mathrm{mg}), m_{1}$ is the accurate mass of samples after self-corrosion test (mg), $t$ is the corrosion time (hour) and $S$ is the area of the sample $\left(\mathrm{cm}^{2}\right)$.

Secondly, the polarization curves and electrochemical impedance spectroscopy (EIS) tests were carried out by the AutolabAT302N electrochemical workstation. A standard three-electrode system was adopted, where the working electrode was the treated sample $(10 \times 10 \mathrm{~mm})$ and the counter and reference electrodes were Pt foil and saturated calomel electrode (SCE), respectively. During the potentiodynamic polarization curve test, the working electrode was immersed in the $5 \% \mathrm{NaCl}$ solution for $900 \mathrm{~s}$, then polarization curves were obtained at a scanning speed of $1 \mathrm{mV} / \mathrm{s}$ with the potential ranging from OCP $-0.2 \mathrm{~V}_{\mathrm{SCE}}$ to OCP $+0.2 \mathrm{~V}_{\mathrm{SCE}}$. Furthermore, the electrochemical impedance spectroscopy (EIS) was measured in the frequency range of 0.1-100000 Hz.

\section{Results and Discussion}

Figure 1 shows the XRD patterns of the recycled as-cast magnesium alloy and commercialized as-cast magnesium alloy samples. It can be referred that the main phases in the samples are $\mathrm{Mg}$ phases. Some second phases are also revealed in the XRD patterns, which are indexed as $\mathrm{Mg}_{17} \mathrm{Al}_{12}$. 


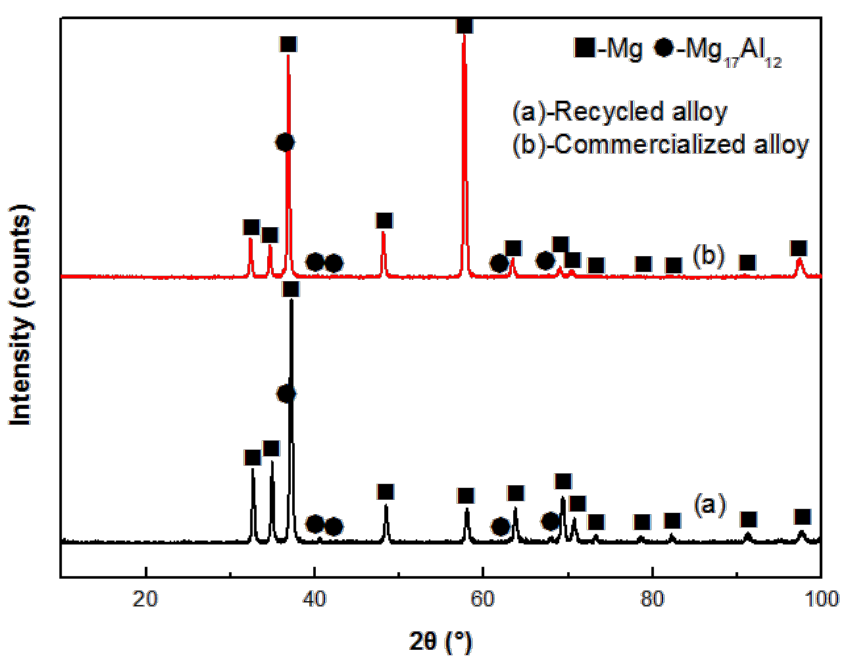

Fig. 1 XRD patterns of the two as-cast magnesium alloys

Figure 2 displays the metallurgical microscope photos of the two as-cast alloys. It can be observed that the two alloys both consist of $\alpha$-Mg solid solutions and the second phases $\mathrm{Mg}_{17} \mathrm{Al}_{12}$, which have been indexed in XRD patterns. The $\mathrm{Mg}_{17} \mathrm{Al}_{12}$ phases are mainly distributed along the grain boundaries. It can be noticed that the grains of the commercialized alloy are apparently larger than those of the recycled alloy. The recycled magnesium alloy has higher content of Al, which could bring forth more obvious effect on grain refinement during the smelting process. The microstructure characteristics of the samples are consistent with the reports from other literature [8, 9].
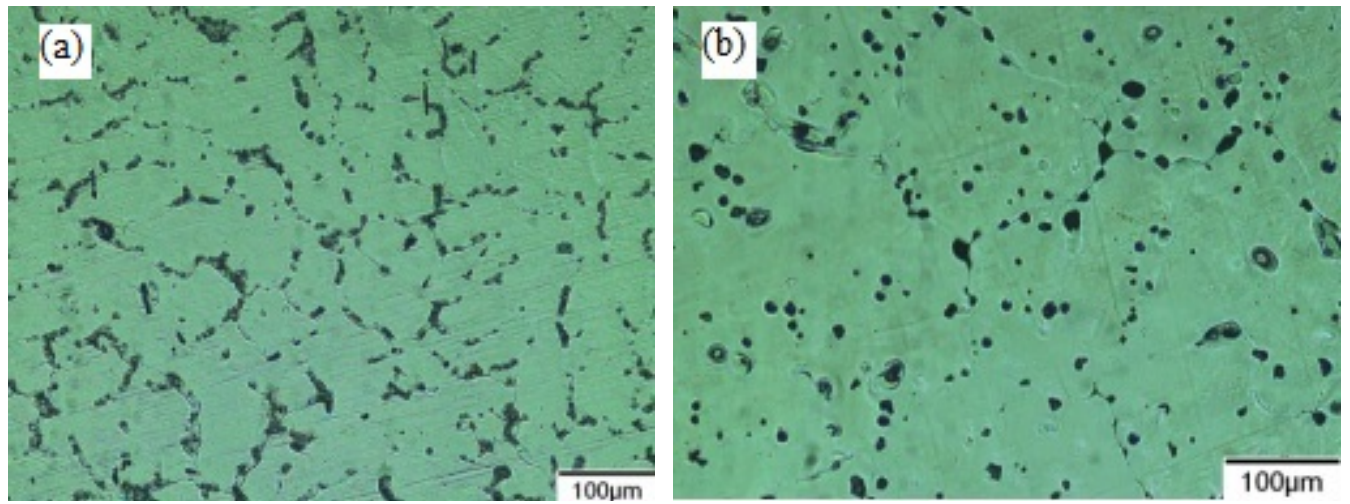

Fig. 2 Metallurgical microscope photos of the as-cast magnesium alloy samples: (a) recycled alloy, (b) commercialized alloy

Figure 3 presents potentiodynamic polarization curves of the as-cast alloys in $5 \% \mathrm{NaCl}$ solution. The two curves of the alloys are smooth and possess similar trend of change. It can be noticed that, there is slight difference of negative corrosion potential between the recycled alloy and the commercialized alloy. Meanwhile, the recycled alloy exhibits a bit higher corrosion current density with the same order of magnitude as the commercialized alloy. These results imply that the recycled magnesium alloy performs similar electrochemical activity to the commercialized alloy [6]. 


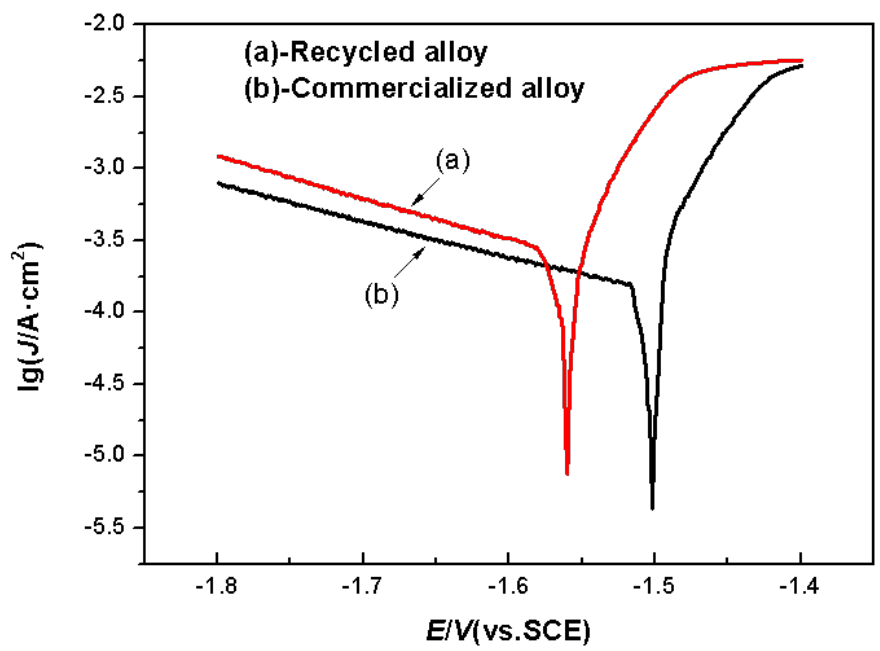

Fig. 3 Potentiodynamic polarization curves of as-cast alloys in $5 \% \mathrm{NaCl}$ solution

The corrosion rates of the as-cast alloys in $5 \% \mathrm{NaCl}$ solution for $168 \mathrm{hrs}$ are given in Table 1 . It can be seen that the recycled alloy exhibits a higher corrosion rate than the commercialized alloy. It should be correlated with the higher corrosion current density for the recycled magnesium alloy, which is shown in Figure 3. Thus the recycled alloy exhibits worse corrosion resistance than the commercialized alloy. Considering the composition of the alloys, the recycled alloy has more Fe content than the commercialized alloy. The high Fe content might be responsible for the worse corrosion behavior of the materials.

Table 1 Free corrosion of as-cast alloys in 3.5\% NaCl solution

\begin{tabular}{ccc}
\hline Material & $\begin{array}{c}\text { Free corrosion rate } \\
\left(\mathrm{mg} \cdot \mathrm{h}^{-1} \cdot \mathrm{cm}^{-2}\right)\end{array}$ & Mass loss(mg) \\
\hline Recycled alloy & 0.169 & 171.80 \\
Commercialized alloy & 0.060 & 61.10 \\
\hline
\end{tabular}

Figure 4 shows the corrosion macroscopic images of the as-cast alloys in $5 \% \mathrm{NaCl}$ solution for 168 hrs observed by optical microscope. As can be seen from Figure 4, after the self-corrosion process, there is much white stuff on the sample surfaces, similar to that on the recycled AZ91 magnesium alloys reported by ref.[5]. However, the visual appearance of the recycled as-cast alloy sample after corrosion is quite different from the commercialized alloy. The recycled alloy possesses a lot of deep corrosion pits on the sample surface whereas there are less corrosion pits on the surface of the commercialized alloy. Additionally, the recycled alloy has more oxide inclusions. These results further indicate that the recycled alloy exhibits worse corrosion resistance.
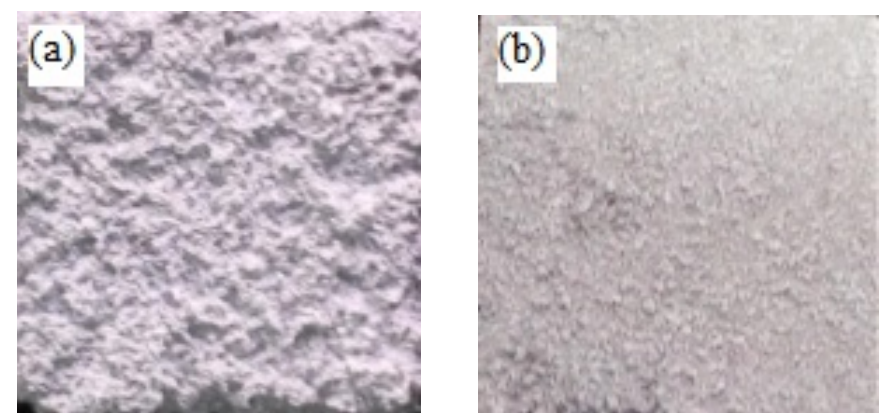

Fig. 4 Macroscopic images after corrosion for the two as-cast alloys: (a) recycled alloy, (b) commercialized alloy

Figure 5 shows the XRD pa tterns of the corrosion products. According to the XRD patterns, 
most white stuff on the two sample surfaces is $\mathrm{Mg}(\mathrm{OH})_{2}$. Meanwhile, $\mathrm{NaCl}$ powder peaks can also be observed. The formation of $\mathrm{Mg}(\mathrm{OH})_{2}$ can be described as following electrochemical reaction equations.

$$
\mathrm{Mg}(\mathrm{s})+2 \mathrm{H}_{2} \mathrm{O}_{(\mathrm{aq})} \rightarrow \mathrm{Mg}(\mathrm{OH})_{2(\mathrm{~s})}+\mathrm{H}_{2} \uparrow(\mathrm{g})
$$

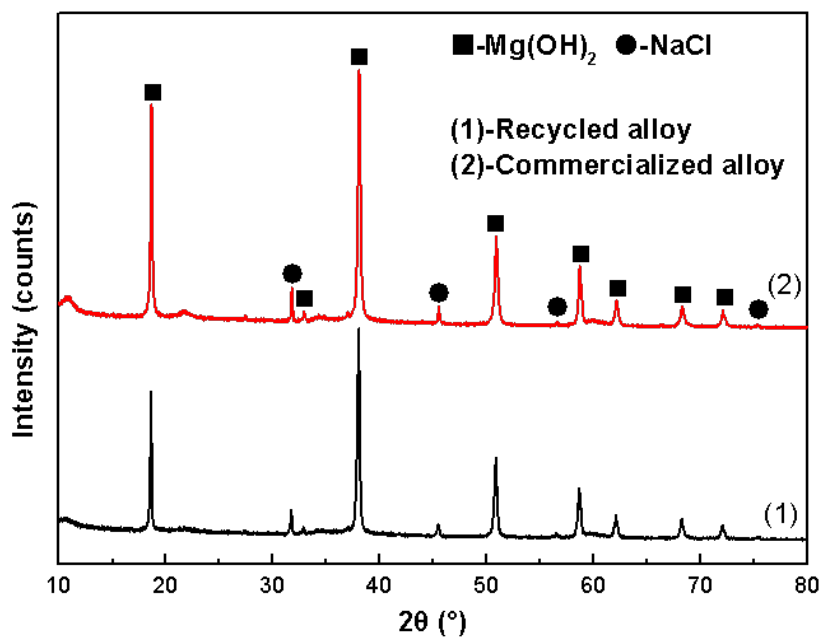

Fig. 5 XRD patterns of corrosion products of the as-cast alloys

Fig.6 shows the EIS results of the two as-cast alloys. EIS consists of high frequency reactance arc and low frequency inductance arc. The diameter of the high frequency reactance arc can reflect the corrosion resistance of the alloys [6]. The greater the diameter of the arc, the higher the corrosion resistance of the alloy. The occurrence of low frequency inductive arc is related to the intermediate product formed during the dissolution of magnesium alloy electrode. It is noticed that, in the high frequency reactance area, the arc diameter of the recycled alloy is a bit smaller than that of the commercialized alloy, which means the recycled alloy has a bit lower corrosion resistance than the commercialized alloy. This result is consistent with the above discussion for the potentiodynamic polarization curves and self-corrosion rates.

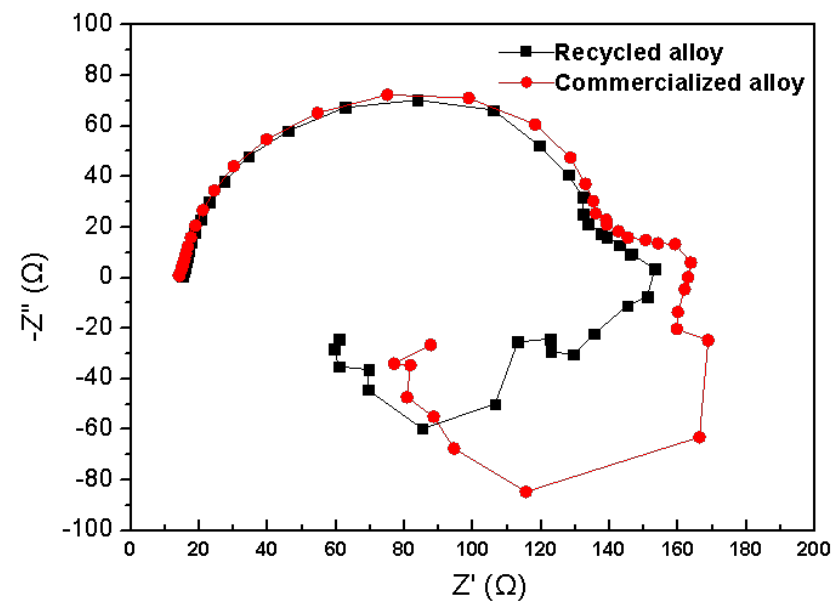

Fig. 6 EIS patterns of the as-cast alloys in $5 \% \mathrm{NaCl}$ solution

\section{Conclusion}

Recycled as-cast magnesium alloys were prepared by smelting method. Their nominal composition meets those of the AZ31 magnesium alloys of national standards. XRD patterns show that the main phases of the recycled magnesium alloys are $\alpha-\mathrm{Mg}$ solid solutions besides a small amount of $\mathrm{Mg}_{17} \mathrm{Al}_{12}$ second phases. Polarization curves results obtained from electrochemical experiments in 5\% $\mathrm{NaCl}$ solution indicate that the recycled AZ31 alloy exhibits a bit higher corrosion current density 
than the commercialized AZ31 magnesium alloy and similar negative equilibrium potential to the commercialized AZ31 magnesium alloy. The recycled alloy performs the higher corrosion rate in 5\% $\mathrm{NaCl}$ solution and the worse corrosion resistance than the commercialized alloy according to self-corrosion test and EIS Measurements.

In a word, it seems that the recycled magnesium alloys cannot substitute the commercialized alloys due to the lower corrosion resistance for the recycled alloys. However, it can be optimistically predicted that electrochemical properties for the recycled alloys will be improved by means of modifying the melt method for preparing the alloys and composition of the alloys.

\section{Acknowledgments}

This work was supported by Gaoyuan Discipline of Shanghai-Environmental Science and Engineering (Resource Recycling Science and Engineering), the graduate fund program (EGD17YJS029) and the Key Subject Construction Project (Material Science, XXKZD1601) from Shanghai Polytechnic University.

\section{References}

[1] A. Dziubinska, A. Gontarz, A new technology for producing AZ31 magnesium alloy aircraft brackets with a triangular outline, Aircr. Eng. Aerosp. Tech. 88 (2016) 452-457.

[2] F. Pan, M. Yang, X. Chen, A Review on Casting Magnesium Alloys: Modification of Commercial Alloys and Development of New Alloys, J. Mater. Sci. Tech. 32 (2016) 1211-1221.

[3] S. Abbasi, M. Aliofkhazraei, H. Mojiri, M. Amini, M. Ahmadzadeh, M. Shourgeshty, Corrosion behavior of pure Mg and AZ31 magnesium alloy, Prot. Met. Phys. Chem. 53 (2017) 573-578.

[4] D. Li, M. Hu, H. Wang, W. Zhao, Low temperature mechanical property of AZ91D magnesium alloy fabricated by solid recycling process from recycled scraps, Trans. Nonferr. Metal Soc. 21 (2011) 1234-1240.

[5] R. Lucci, R.L. Padilla, S. Cantero, R. Bariles, C. Oldani, Refining of AZ91 Magnesium Alloy Obtained in Machining Chips Recycling, Proc. Mater. Sci. 8 (2015) 886-893.

[6] J. Deng, G. Huang, Y. Zhao, B. Wang, Electrochemical Performance of AZ31 Magnesium Alloy under Different Processing Conditions, Rare Metal Mat. Eng. 43 (2014) 0316-0321.

[7] S. Arthanari, R. Nallaiyan, S.K. Seon, Electrochemical corrosion behavior of acid treated strip cast AM50 and AZX310 magnesium alloys in 3.5 wt.\% NaCl solution, J. Magnesium Alloys. 5 (2017) 277-285.

[8] G. Buffa, D. Campanella, L. Fratini, F Micari, AZ31 magnesium alloy recycling through friction stir extrusion process, Int. J. Mater. Forming, 9 (2016) 613-618.

[9] M. Hu, Z. Ji, X. Chen. Effect of extrusion ratio on microstructure and mechanical properties of AZ91D magnesium alloy recycled from scraps by hot extrusion, Trans. Nonferr. Metal Soc. 20 (2010) 987-991. 